\title{
Optimal Timing to Invest in E-commerce
}

\author{
Jow-Ran Chang \\ National Tsing Hua University \\ Mao-Wei Hung \\ National Taiwan University
}

\begin{abstract}
The timing of investment in e-commerce remains hotly debated in both the academic and investment communities. This study develops a framework for analyzing the optimal timing for a company to invest in e-commerce for conducting its business-to-business (B2B) or business-to-consumer (B2C) transactions. This study applies a real option theory to assess a new risk-reward dynamic for investing in e-commerce. The numerical results demonstrate that the optimal timing of investment in e-commerce depends on uncertainties regarding future cash flows and the opportunity costs associated with e-commerce. Implications with regard to the behavior of Internet companies from a financial perspective are discussed. $\odot 2006$ Wiley Periodicals, Inc.
\end{abstract}

E-commerce business has been growing rapidly during recent years. The Census Bureau of the Department of Commerce reported that total e-commerce sales for 2004 were estimated at $\$ 69.2$ billion, an increase of $23.5 \%$ from 2003 in the United States. In comparison, total retail sales for 2004 increased just 7.8\% from 2003. E-commerce sales in 2004 accounted for $1.9 \%$ of total sales, up from $1.6 \%$ in 2003 . Regarding global e-commerce figures, at the end of 2004, the United States had nearly 186 million internet users and worldwide the number of users exceeded 945 million (ETForecasts, 2005). 
The success of e-commerce business is a key question. Lubbe and Pather (2002) denoted that adding business value through e-commerce investment is probably a key organizational concern of CEOs. The role of information technology (IT) has also been redefined by some organizations to include attempts to engage in e-commerce operations. Quayle (2003) observed that no relationship exists between organizational performance and the proportion of resources allocated to IT. Moreover, Kearns (2004) stated that although IT investment potentially can provide competitive advantage, actual returns on such investment vary significantly and most CEOs rate past IT investment as being disappointing. Lubbe (2004) studies the existence of a link between organizational performance and information technology investment intensity in SME organizations using e-commerce for the period 2001/2002.

A growing body of research exists on e-commerce investment, but a comprehensive understanding of the optimal timing for a company to invest in e-commerce remains elusive. Raghunathan and Madey (1999) designed a firm-level framework for electronic commerce information systems (ECIS) infrastructure planning. Moreover, McDonald and Siegel (1986) proposed that the option to defer uncertain investment is very valuable and should be considered by companies making investment decisions. Kulatilaka and Perotti (1998) noted that the benefits of early preemptive investment may exceed the benefits of waiting given intense competition.

E-commerce investment has two main characteristics. First, expenditures are partly irreversible. Restated, sunk costs cannot be recovered. Second, the optimal timing for investment in e-commerce can be delayed. That is, the company can wait for new information regarding prices, costs, and other market conditions before investing in e-commerce. In most books, the income approach, cost approach, market approach, discount cash flow, and real option method, all of which may be combined with game models, are mentioned, as, for example, in Amram, Kulatilaka, and Henderson (1999). All of these approaches are adopted in reality, but none of them are satisfactory. However, the real option method is superior to the others when uncertain future situations involving well-defined models are considered. Unlike standard corporate resource allocation approaches, the real options approach recognizes the importance of managerial flexibility and strategic adaptability. Recently, Benaroth and Kauffman (2000) and Taudes, Feurstein, and Mild (2000) applied the real options theory to real-world examples.

Real options are derived from financial options, and are used to price investment projects. Several studies have examined real options. Tourinho (1979) demonstrated that natural resource reserves can be viewed as options that produce a resource and are valued accordingly. Moreover, Cukierman (1980) and Bernanke (1983) designed models 
in which firms have an incentive to postpone irreversible investment decisions until the arrival of new information. The survey articles by Dixit (1992) and Pindyck (1991) mention other studies. Cortazar and Schwartz (1998) applied the flexible Monte Carlo simulation to assess the real option in relation to an oil field. Additionally, Pindyck (1999) analyzed the long-term behavior of oil prices and their effect on real options. Finally, Dias (2002) provided an overview of the exploration and production of real options models.

The real option valuation method has been applied in e-commerce business for several years. However, few works have considered investment time horizon. Bicher and Ahnefeld (2002) applied and tested a variation of the real option method designed for private equity investments. The case-study approach is applied to discuss the case of a fictitious company involved in B2B during the year 2000. Li and Johnstone (2002) considered the real options theory in relation to strategic IT investment. They divided IT investment opportunities into four categories according to two criteria: technology switching costs and nature of competition. This study applies a real option approach to describe the timing of firm investment in e-commerce. This investigation presents a jump diffusion process for describing the new dynamic of investing in e-commerce. Unlike traditional diffusion processes, jump diffusion can determine the influence of catastrophic economic shocks or jump events on project value. The numerical results presented in this work demonstrate that three distinct components help to determine the optimal time for launching e-commerce. The first component is the project value volatility. The critical value of the project increases with volatility, thus reducing the actual investment required of the company. The second component is the size of the jump in the project value. The investment opportunity value decreases with increasing jump size. This smaller investment opportunity value leads to smaller opportunity cost for investing now rather than waiting. Finally, the third component is the jump probability of the project. The critical value of the project increases with increasing jump probability, which thus increases the investment amount.

\section{METHODOLOGY}

Before designing the proposed methodology, this study presents an example to illustrate to readers the investment timing problem. A company faces an e-commerce investment. The company plans to spend $\$ 100$ to construct an e-commerce information system. However, because e-commerce remains immature, the company is unsure about the acceptance of e-commerce by its customers. Assuming that the uncertainty regarding e-commerce information systems can be resolved during the next year, the company is trying to maximize the 
expected return from its $\$ 100$ investment. According to the firm estimates, the e-commerce information system has a $50 \%$ chance of being widely accepted during the next year. If the e-commerce information system becomes popular during the next year, the expected increase in cash inflow from this investment is estimated to reach $\$ 16$ a year. If the e-commerce information system does not become popular during the next year, the expected annual net cash inflow from this investment will be $\$ 6$. Assuming that the discount rate for this investment is $10 \%$, the net present value (NPV) of this investment can be calculated as:

$$
N P V=-100+\sum_{i=1}^{\infty} \frac{16+6}{(1+10 \%)^{t}} * 0.5=10
$$

Suppose that the company waits 1 year to monitor market acceptance of the new e-commerce technology and then decides to proceed with the investment if the reaction is favorable or otherwise give up the investment. The NPV of the investment then can be calculated as:

$$
N P V_{1}=\frac{0.5}{(1+10 \%)}\left[-100+\sum_{i=1}^{\infty} \frac{16}{(1+10 \%)^{i}}\right]=27.27
$$

Basically, this example demonstrates that the value of option of deferring investment. However, in the event of industrywide uncertainty, waiting has no value, owing to the asymmetric effects of uncertainty, such as the influence of random competitive arrivals. Intuitively, competitive pressure will reduce the value of the option of deferring an e-commerce investment.

Recognizing the potential of real options in capital budgeting, the theoretical model presented here can be used to optimize the timing of a firm investing in e-commerce investment decisions made by a manager. This study considers the problem of determining the point at which it is optimal to pay a sunk cost $I$ in return for a project whose value is $P$, given that $P$ evolves according to the following mixed Brownian motion and jump process:

$$
d P=g P d t+\sigma P d B+P d J
$$

where $d B$ denotes the increment of a Wiener process and $d J$ represents the increment of a Poisson process with mean arrival rate $\lambda$, and $d B$ and $d J$ are independent. This work assumes that if an event occurs $J$ reduces by some fixed percentage $u$ with probability 1 . That is

$$
d J= \begin{cases}0 & \text { with probability } 1-\lambda d t \\ u & \text { with probability } \lambda d t .\end{cases}
$$

Equation (1) implies that the current value of the project is known, but $P$ fluctuates like a geometric Brownian motion, and over each time interval $d t$ there is a small probability that $\lambda d t$ will drop to $(1-u)$ times its 
original value. Therefore, the future value of the project remains uncertain despite the continuous arrival of new information. Equation (1) is an abstraction from the e-commerce investment. Uncertainty is sometimes discrete, resembling a jump in the $P$ process. Competitors enter the industry with better e-commerce technology or stricter new regulations, thus destroying the value of existing business.

A company's investment opportunity is equivalent to a perpetual call option. Moreover, manager investment decisions involve deciding when to exercise such an option. Consequently, investment decisions can be considered valuation problems.

The following section denotes the value of the investment option by $V(P)$. This study attempts to maximize expected present value of the payoff from investing at time $\mathrm{T}$ :

$$
V(P)=\max E\left[\left(P_{T}-I\right) e^{-r T}\right]
$$

where $E$ denotes the expectation, $r$ represents the discount rate, and the maximization of the expected present value is subject to Eq. (1) for $P$. If $g>r$, waiting longer is a better policy and the optimum would exist. To understand this problem, this study assumes that $g<r$. $\delta$ is defined as the difference of $r-g$ and $\delta>0$.

The only return from the holding project, $V(P)$, is its capital appreciation. The project yields no cash flows up to time $T$. The optimal investment rule can be derived with the use of a dynamic program. Consequently, the Bellman equation can be presented as

$$
r V d t=E(d V)
$$

Equation (4) implies that over time interval $d t$, the total expected return from the project, $r V d t$, equals its expected rate of capital appreciation. This study expands $d V$ with the use of Ito's lemma for the combined Brownian and Poisson processes. Then

$$
r V d t=g P V^{\prime}(P) d t+\frac{1}{2} \sigma^{2} P^{2} V^{\prime \prime}(P) d t-\lambda\{V(P)-V[(1-u) P]\} d t
$$

Given $g=r-\delta$, the Bellman equation becomes the following differential equation, which must be satisfied by $V(P)$ :

$$
\frac{1}{2} \sigma^{2} P^{2} V^{\prime \prime}(P)+(r-\delta) P V^{\prime}(P)-(r+\lambda) V(P)+\lambda V[(1-u) P]=0
$$

Next, the boundary is considered. First, the limiting behavior of $V(P)$ near zero yields the first condition:

$$
V(0)=0
$$

Equation (7) means that the option to invest has no value when $P=0$.

The investment rule presented here has the form of the critical value $P^{*}$ such that the optimal timing for investing is when $P>=P^{*}$. The other 
two conditions stem from the concern of this study with optimal investment. The behavior of $V(P)$ at $P^{*}$ is considered. At this threshold, it becomes optimal to exercise the option, and therefore acquire the project with value $P^{*}$ by incurring the exercise price of investment $I$. However, two conditions must be fulfilled. The first condition is that the value of the option must equal the net value obtained by exercising it; this is the value-matching condition:

$$
V\left(P^{*}\right)=P^{*}-I
$$

Equation (8) has another interpretation. We could write the equation as $P^{*}-V\left(P^{*}\right)=I$. The project is valued $P$, but involves giving up the opportunity or option to invest, which is valued at $V(P)$ when the company invests in the e-commerce project. Hence, the gain associated with the project is $P-V(P)$ and the critical value $V^{*}$ indicates where this net gain equals the direct cost of investment $I$.

The second condition is that the graphs of $V(P)$ and $P-I$ should meet tangentially at $P^{*}$; this is the smooth-pasting condition:

$$
V^{\prime}\left(P^{*}\right)=1
$$

Equation (9) indicates that if $V(P)$ was not continuous and smooth at the critical exercise point $V^{*}$, better results could be achieved by exercising this option at a different point.

To identify $V(P)$, Eq. (6) must be solved subject to the boundary conditions (7)-(9). Functional forms can be guessed, and substitution used to determine whether they work. Equation (6) is simply a second order homogeneous linear equation. To satisfy boundary condition (7), the solution of Eq. (6) must be denoted as

$$
V(P)=A P^{\beta_{1}}
$$

where constant A remains to be determined, and $\beta_{1}>1$ is a known constant with a value that depends on parameters $\sigma, r$, and $\delta$ of the differential equation.

The remaining boundary conditions, as well as Eqs. (8) and (9), can be used to identify the two remaining unknowns, constant A and critical value $P^{*}$, at which it is optimal to invest. Substituting (10) into Eqs. (8) and (9) and rearranging yields

$$
P^{*}=\frac{\beta_{1}}{\beta_{1}-1} I
$$

and

$$
A=\frac{P^{*}-I}{\left(P^{*}\right)^{\beta_{1}}}=\frac{\left(\beta_{1}-1\right)^{\beta_{1}-1}}{\left(\beta_{1}\right)^{\beta_{1}} I^{\beta_{1}-1}}
$$

Equations (10) and (12) provide the value of the investment opportunity; that is, the option value of the e-commerce project $V(P)$. Meanwhile, Eq. (11) yields the optimal investment rule, namely, the critical value $P^{*}$ at which it is optimal to invest. When $\beta_{1}>1$, then $\beta_{1} /\left(\beta_{1}-1\right)>1$ and $P^{*}$ 
$>I$. Therefore, the traditional net present value ( NPV) rule is incorrect. Uncertainty and irreversibility drive a wedge between the critical value $P^{*}$ and $I$. Consequently, it is important to examine its magnitude for realistic values of the underlying parameter $\beta_{1}$ and its response to changes in these parameters.

A key question is the value of $P$ for which immediate investment is optimal. If $P>P^{*}$ then immediate investment in e-commerce projects is desirable. Therefore, investment timing or rules can be expressed in terms of $V(P)$ as

$$
V(P)=\left\{\begin{array}{lll}
A P^{\beta_{1}} & \text { for } & P \leq P^{*} \\
V-I & \text { for } & P>P^{*}
\end{array} .\right.
$$

Substitute Eq. (10) into (6); then, yields a positive solution to a nonlinear equation:

$$
\frac{1}{2} \sigma^{2} \beta(\beta-1)+(r-\delta) \beta-(r+\lambda)+\lambda(1-u)^{\beta}=0
$$

The value of , that satisfies Eq. (14) can be found numerically. Then, given $\beta_{1}, P^{*}$ and A can be derived from Eqs. (11) and (12). If $u=1$ (so that the event is $P$ falling to zero), then Eq. (14) can be simplified to produce a quadratic equation:

$$
\frac{1}{2} \sigma^{2} \beta(\beta-1)+(r-\delta) \beta-(r+\lambda)=0
$$

The two roots are

$$
\beta_{1}=\frac{1}{2}-\frac{r-\delta}{\sigma^{2}}+\sqrt{\left(\frac{r-\delta}{\sigma^{2}}-\frac{1}{2}\right)^{2}+\frac{2(r+\lambda)}{\sigma^{2}}}>1
$$

and

$$
\beta_{2}=\frac{1}{2}-\frac{r-\delta}{\sigma^{2}}-\sqrt{\left(\frac{r-\delta}{\sigma^{2}}-\frac{1}{2}\right)^{2}+\frac{2(r+\lambda)}{\sigma^{2}}}<0
$$

so the general solution to Eq. (6) can be represented as

$$
V(P)=A_{1} P^{\beta_{1}}+A_{2} P^{\beta_{2}}
$$

where $A_{1}$ and $A_{2}$ are constants requiring determination. In the present problem, the boundary condition (7) implies that $A_{2}=0$. 


\section{NUMERICAL ANALYSIS}

The characteristics of the optimal investment timing and the value of the e-commerce project can now be examined, as indicated by Eqs. (10)-(13). Numerical results help to illustrate how they depend on the values of the various parameters.

In each case, unless otherwise noted, the cost of investment is set as follows: $I=1, r=0.04, \delta=0.04, \sigma=0.2, u=0.4$, and $\lambda=0.1$. Figure 1 illustrates a function of $V$ for these parameter values, as well as for $\sigma=$ $0, \sigma=0$. 3. The tangency point of $V(P)$ with the line $P-I$ gives the critical value $P^{*}$. Moreover, the opportunity cost is $V(P)$. When $P<P^{*}$, then $V(P)>P-I$ and $P<I+V(P)$, the value of the project is below its full cost, and the direct cost $I$ is added to the opportunity cost $V(P)$.

Figure 2 shows the dependence of $P^{*}$ on $\sigma$. Notably, $P^{*}$ increases markedly with $\sigma . P^{*}$ increases with increasing $\sigma$, which tends to depress investments. This phenomenon occurs because investments are highly sensitive to volatility in project values, regardless of investor risk preferences.

Figures 3 and 4 show the dependence of $V(P)$ and $P^{*}$ on $u$. Notably, an increase in $u$ from 0 to 1 causes a decrease in $V(P)$, and consequently a decrease in critical value $P^{*}$. This decrease occurs because a larger $u$ value implies a smaller investment opportunity value, leading to a smaller opportunity cost for investing now rather than later. Firms engaged in e-commerce business face competitors, each trying to develop their own e-commerce businesses, and eventually additional competitors may enter the market, causing $P$ to continue to fall.

A positive $\lambda$ can affect the value of $V(P)$, the opportunity cost of the project, in two ways. First, a positive value of $\lambda$ increases the variance of percentage change in $P$, which tends to increase $V(P)$. Second, a positive value of $\lambda$ reduces the expected rate of capital gain on $P$, thus decreasing $V(P)$. As shown in Figures 5 and 6, the net effect is the reduction of $V(P)$, therefore reducing critical value $P^{*}$.

\section{DISCUSSION}

The precipitous decline in the valuations of e-commerce companies since March 2000 is an interesting phenomenon. Ofek and Richardson (2001) contended that part of the reason for these declines has been an increase in the number of shareholder selling driven by the expiration of lock-up agreements. Garicano and Kaplan (2002) found that after the bursting of the tech bubble in 2000, in valuing B2B and B2C e-commerce businesses, the market reduced its expectations regarding future growth, the extent of transaction cost reductions, the speed of the adoption network effect, and the level of competition. Quayle (2003) pointed out that no relationship exists between organizational performance and the proportion of resources allocated to IT investment. Thus whether a positive 


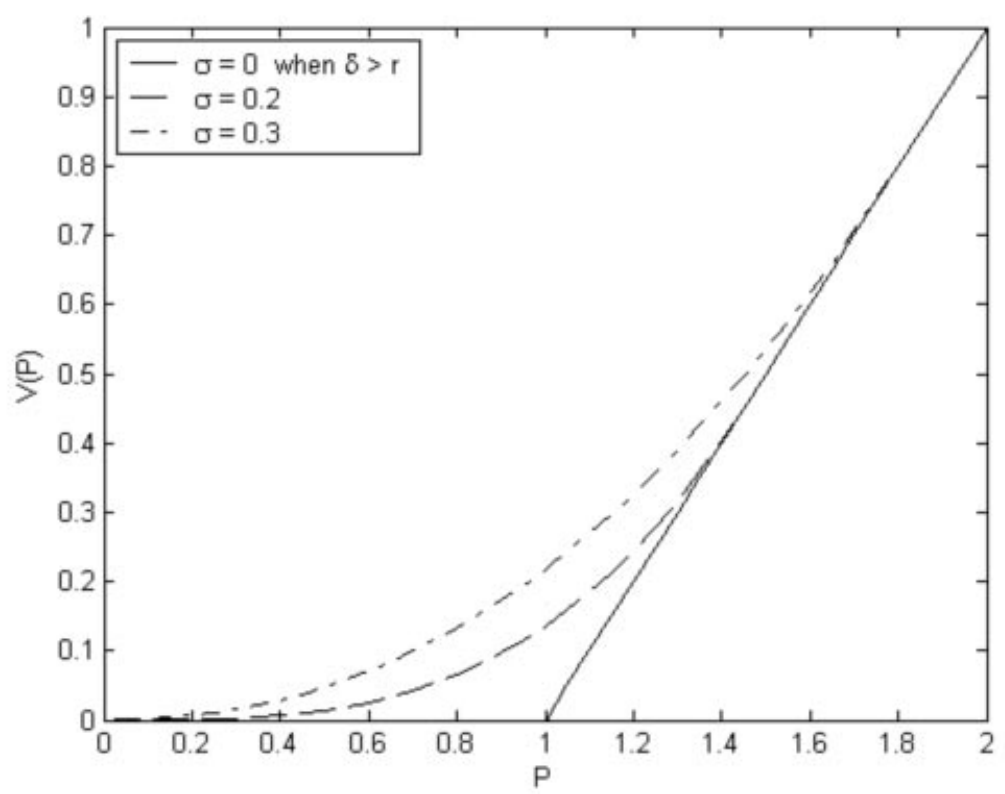

Figure 1. Value of investment $V(P)$ for $\sigma=0,0.2$, and 0.3 .

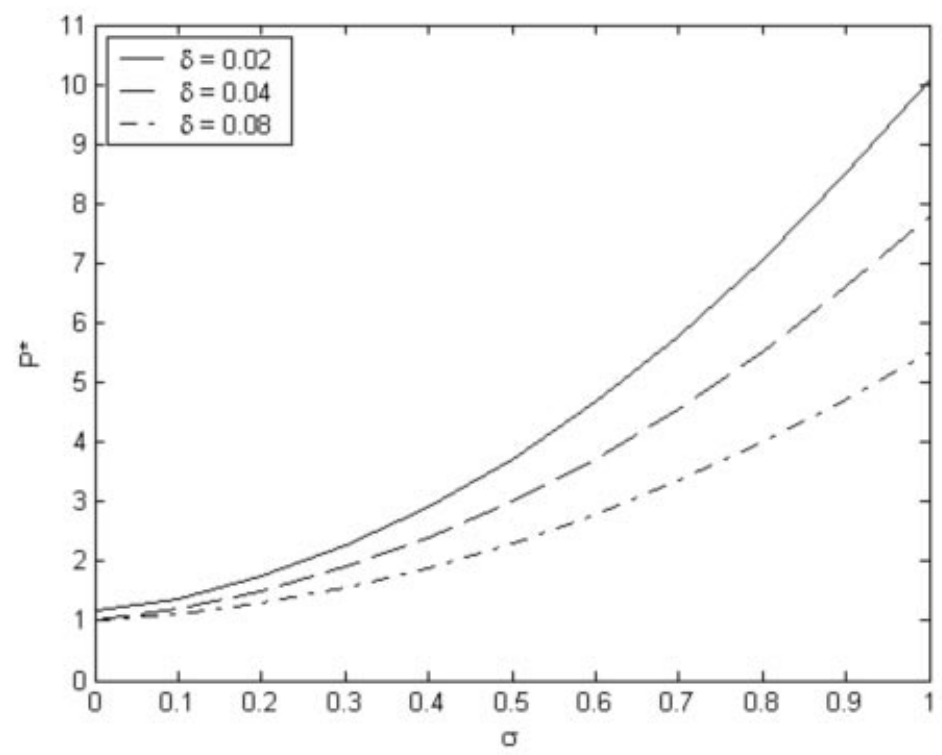

Figure 2. Critical value $P^{*}$ as a function of $\sigma$.

or negative correlation between IT investment and profitability exists in firms with heavy investment in e-commerce remains uncertain.

This study explains that uncertainties facing e-commerce business increase when the market reduces its expectations regarding future 


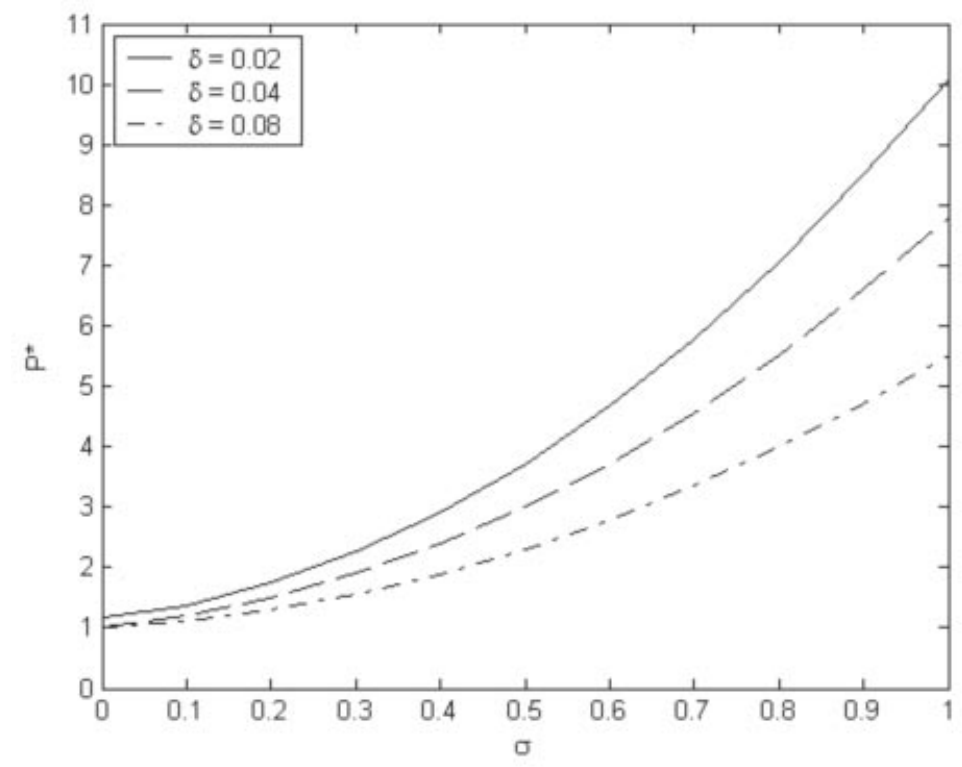

Figure 3. Value of investment $V(P)$ for $u=0,0.4$, and 1.0.

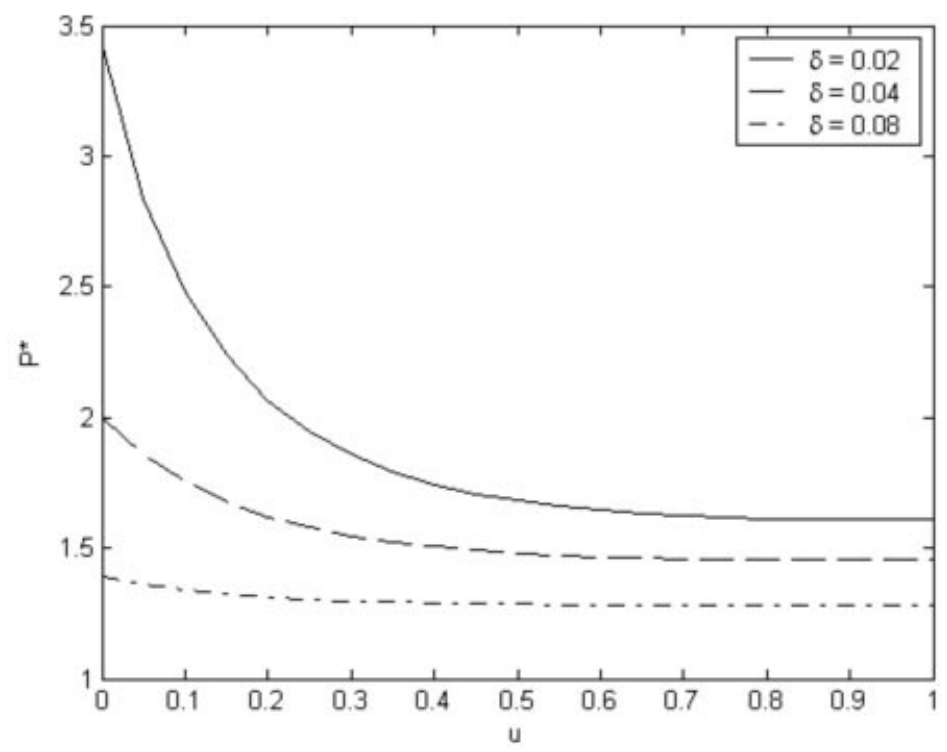

Figure 4. Critical value $P^{*}$ as a function of $u$.

growth. The critical value $P^{*}$ increases with increasing $\sigma$, which tends to depress investment. Thus the optimum strategy to adopt is to wait for the arrival of new information. Investing now will result in large losses for 


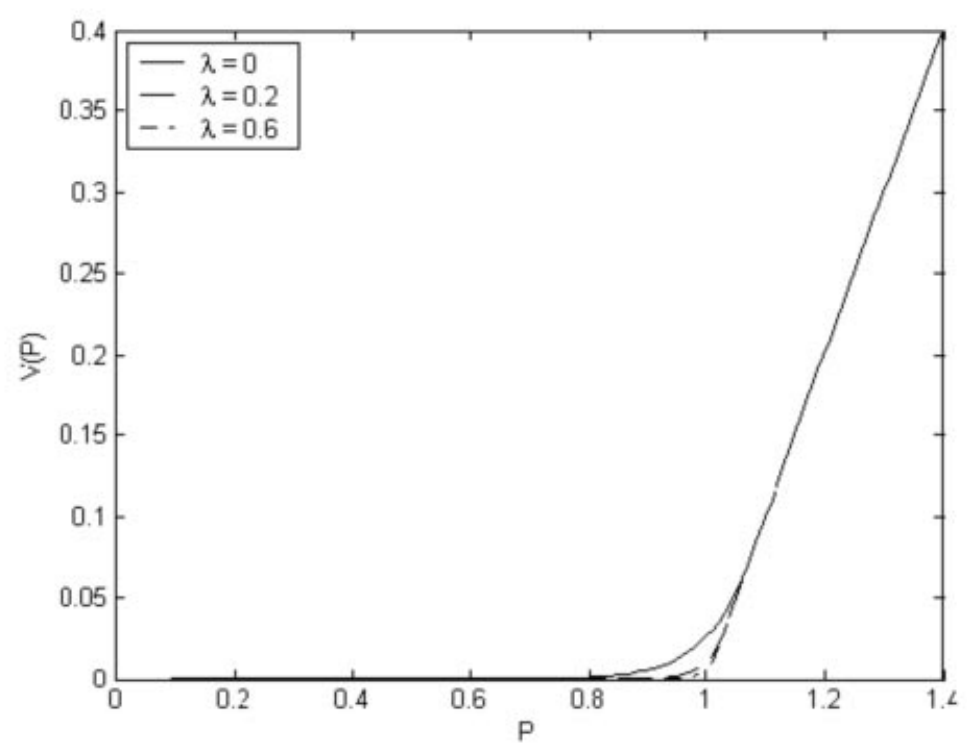

Figure 5. Value of investment $V(P)$ for $\lambda=0,0.2$, and 0.6.

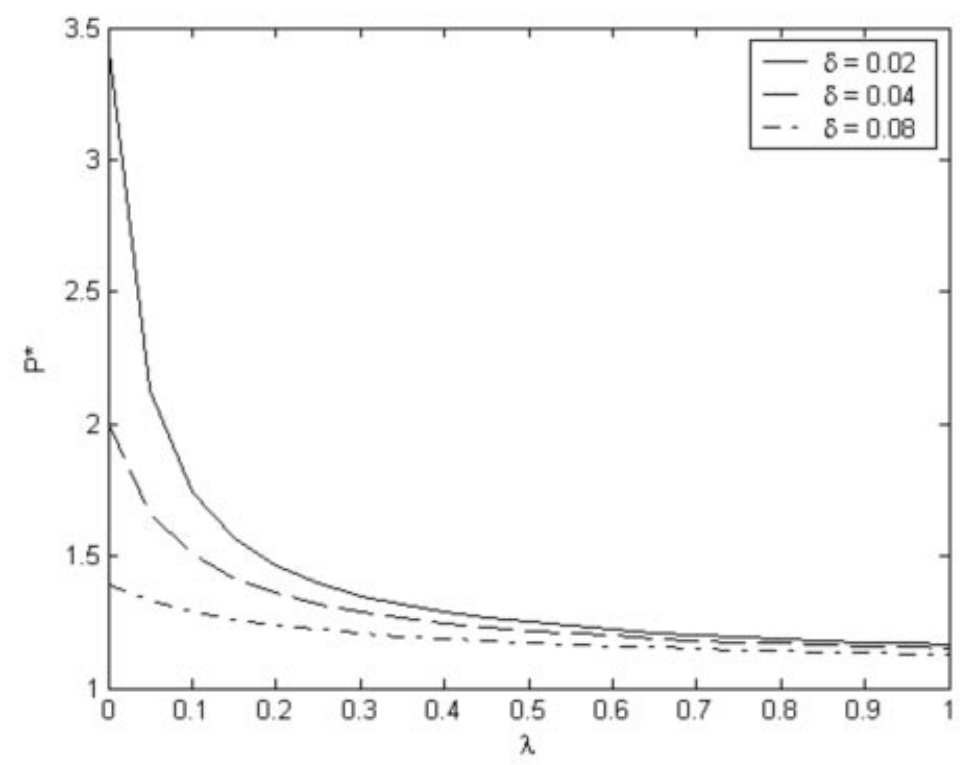

Figure 6. Critical value $P^{*}$ as a function of $\lambda$.

Internet companies. Therefore, the option to defer uncertain investment is very valuable and should be considered by companies making e-commerce investment decisions. Li and Johnson (2002) presented a wireless Internet trading infrastructure example. Li and Johnson observed that 
technology that enables high-speed wireless data access has been available for over a decade. However, no electronic brokerage companies offered wireless trading services before late 1998.

Garicano and Kaplan (2002) proposed an exception for cases like eBay, which provides a service that is not available off-line. It benefits from network effects because it connects large numbers of buyers and sellers. The market share of eBay increases with the number of buyers and sellers using its services. Unlike many other firms involved in e-commerce, the market value of eBay has only declined by a little over $50 \%$ from its tech-bubble peak. In addition, research groups maintain that e-procurement can turn $10 \%$ to $20 \%$ of procurement expenses directly into pretax profit. Moreover, PC Week asserts that more companies are entering an e-procurement market that users now see as providing the fastest return on an e-commerce investment. Ford provides another example, indicating that competition is a more important factor than deferring an e-commerce investment. Ford uses an e-procurement system to establish connection with between 3000 and 5000 suppliers globally.

The framework developed in this study is now applied to explain these cases. Competition reduces profit in the Internet auction market. A jump in e-commerce value can explain the eBay case. An increase in jump size $u$ from 0 to 1 or jump probability $\lambda$ decreases the opportunity cost $V(P)$, and hence the critical value $P^{*}$. The best way for a company to apply ecommerce transaction is to act in a timely fashion. eBay has been extremely efficient and effective in launching and expanding its business and thus has continued to outperform its competitors since 2001.

In conclusion, uncertainty and jump behavior depend on the industry sector in which a firm is completing. Some industry sectors have low uncertainty and high jump behavior. Firms should launch e-commerce transaction systems early, achieving large reduction in transaction costs and boosting further growth by establishing a strong foundation for competitiveness. Other industry sectors are characterized by high uncertainty and low jump behavior, and firms in these sectors should wait for the arrival of further information before deciding the timing of the launch of their e-commerce transaction system.

\section{CONCLUSION}

This article employed a financial framework to analyze the optimal timing for firm introduction of e-commerce to B2B or B2C transactions. This study applies a jump diffusion process to describe the new dynamics involved in investing in e-commerce. The numerical results demonstrate that the timing for firm introduction of e-commerce to its transactions depends on uncertainties regarding future cash flows and the opportunity costs associated with using e-commerce. Discussing the behavior of Internet companies from a financial perspective helps to determine which 
companies should apply e-commerce business early and which companies should wait to obtain new information before investing in e-commerce.

\section{REFERENCES}

Amram, M., Kulatilaka, N., \& Henderson, J. (1999, July 15). Taking an option on IT. CIO Enterprise Magazine [on-line]. Available: http://www.cio.com/ archive/enterprise/061599_opt.html

Benaroth, M., \& Kauffman, R. J. (2000). Justifying electronic banking network expansion using real options analysis. MIS Quarterly, 24, 197-225.

Bernanke, B. S. (1983). Irreversibility, uncertainty, and cyclical investment. Quarterly Journal of Economics, 98, 85-106.

Bicher, A., \& Ahnefeld, M. (2002). Valuing a private equity venture investment: The case of a B2B marketplace start-up. Symposium conducted at the 6th Annual Real Options Conference of Real Option Group, Paphos, Cyprus.

Cortazar, G., \& Schwartz, E. S. (1998). Monte Carlo evaluation model of an undeveloped oil field. Journal of Energy Finance and Develop, 3, 73-84.

Cukierman, A. (1980). The effects of uncertainty on investment under risk neutrality with endogenous information. Journal of Political Economy, 88, 462-475.

Dias, A. G. (2002). Real options in upstream petroleum: Overview of models and applications. Proceedings of the International Real Option Workshop, Turku, Finland, May 6-8, 2002.

Dixit, A. K. (1992). Investment and hysteresis. Journal of Economic Perspectives, $6,107-132$.

ETForecasts. (2005). Internet users forecast by country: An estimate and forecast of Internet users in 57 countries and 6 regions of the world. Available: http://www.etforecasts.com/products/ES_intusersv2.htm

Garicano, L., \& Kaplan, S. N. (2002). Business-to-business e-commerce: Value creation, value capture and valuation. In M. R. Baye (Ed.), The economics of the Internet and e-commerce. New York: Elsevier.

Kearns, G. S. (2004). A multi-objective, multi-criteria approach for evaluating IT investments: Results from two case studies. Information Resources Management Journal, 17, 37-62.

Kulatilaka, N., \& Perotti, E. (1998). Strategic growth options. Management Science, 44, 1021-1030.

Li, X., \& Johnson, J. D. (2002). Evaluate IT investment opportunities using real options theory. Information Resources Management Journal, 15, 32-47.

Lubbe, S. (2004). The impact of IT investment in RSA e-commerce SME organisations. Electronic Journal of Information Systems Evaluation, 7, 49-56.

Lubbe, S., \& Pather, S. (2002). A study into theoretical success factors for successful Internet commercial enterprises. In: European Conference on Information Technology Evaluation, Paris, July 15-16, 2002.

McDonald, R. L., \& Siegel, D. R. (1986). The value of waiting to invest. Quarterly Journal of Economics, 101, 331-349.

Ofek, E., \& Richardson, M. (2001). Dotcom mania: The rise and fall of Internet stock prices (Working Paper No. 8630). Cambridge, MA: NBER.

Pindyck, R. S. (1991). Irreversibility, uncertainty, and investment. Journal of Economic Literature, 29, 1110-1148. 
Pindyck, R. S. (1999). The long-run evolution of energy prices. Energy Journal, $20,1-27$.

Quayle, M. (2003). E-business in a turbulent world: Usage in European small and medium enterprises. Internal Journal Electric Business, 1, 41-52.

Raghunathan, M., \& Madey, G. R. (1999). A firm level framework for planning electronic commerce information system infrastructure. Internal Journal Electric Commerce, 4, 121-145.

Taudes, A., Feurstein, M., \& Mild, A. (2000). Options analysis of software platform decisions: A case study. MIS Quarterly, 24, 227-243.

Tourinho, O.A. (1979). The valuation of reserves of natural resources: An option pricing approach. Unpublished Ph.D. dissertation, University of California, Berkeley.

Correspondence regarding this article should be sent to: Mao-Wei Hung, National Taiwan University, 50, Lane 144, Keelung Road, Section 4, Taipei 106, Taiwan (hung@management.ntu.edu.tw). 